\title{
Economic and Mathematical Modeling of Food Security Level in View of Import Substitution
}

\author{
Aleksey Rogachev ${ }^{1}$ \\ ${ }^{1}$ Volgograd State Agrarian University, Volgograd, Russia \\ Correspondence: Aleksey Rogachev, Volgograd State Agrarian University, Ap. 109, 6, Sovetskaya str., \\ Volgograd, 400066, Russia. Tel: 79-27-257-9342. E-mail: rafr@mail.ru
}

Received: June 1, 2015 Accepted: June 22, 2015 Online Published: July 15, 2015

doi:10.5539/ass.v11n20p178

URL: http://dx.doi.org/10.5539/ass.v11n20p178

\begin{abstract}
Strategy of development of any country's economy supposes the purpose of achieving and preserving food security which is determined as the state's capability, guaranteed by corresponding resource potential, to satisfy independently from external and internal conditions and in stable manner - the need of country's population on the whole and of each citizen for food products and drinking water in volumes, assortment, and quality, sufficient for full physical and social development, health support, and provision of expanded reproduction. The problem of provision of food security remains topical since the start of liberalization of foreign economic policy in Russia. The authors of the article use the mathematical tool of fuzzy logic to develop economic \& mathematical model of evaluation of the level of food security in view of import substitution. By the example of the Russian Federation, the authors show the manifestation of the problem of food security under the modern conditions, and how this problem can be solved with the help of import substitution. The developed economic \& mathematical model allows modeling the functioning of the system through setting the corresponding components of vectors. Implementation of the offered food model allows receiving integral evaluation of the state of food security and determining comparative characteristics of the values of threats to food security on the basis of their automatized evaluation.
\end{abstract}

Keywords: food security, economic \& mathematical modeling, modeling the level of food security, import substitution

\section{Introduction}

In all developed countries, the state - with the help of various economic and financial actions and methods (including the system of subsidies and compensations, tax exemptions, reduction of tariffs for resources used by agriculture, system of crediting and insurance with compensations from budget, etc.) - provides constant support for agriculture. This allows not only improving food provision of country's population but exporting large volumes of agricultural production and food products.

New political system of the Russian federation and emerging global economic relations required rethinking of the notion of "food security", specification of its main principles and peculiar features. One of the criteria of food security of citizens is the level, at which at least $80 \%$ of food products, consumed by population, are produces by domestic agrarian sector. This research performs evaluation and modeling of the level of food security in view of import substitution. The subject of the research is food security of modern Russia.

\section{Materials and Methods}

Founding on the totality of theoretical suggestions which treat the food security level of production enterprises as a function of interconnected and exogenous factors, influencing the production, it is possible to evaluate the level of threats with the help of mathematical tool of fuzzy logic which is widely used in the systems of artificial intellect. The offered approach allows evaluating the causes and scales of emergence of crisis situations more adequately and receiving indicative instrumentarium for increasing the level of food security.

Mathematical tool of fuzzy logic is used when existing quantitative and qualitative information is not enough, or it is not sufficient for receiving statistically significant conclusions with the required level of reliability. This approach allows forming the portfolio of project decisions on the basis of fuzzy evaluations of their technical and economic indicators by expert ranking, or solving the formulated task of economic \& mathematical optimization. 
Flexibility and universality of methods of the fuzzy mathematics theory allow viewing them as an effective instrumentarium for solving various perspective tasks of analysis of alternative projects and variants.

As an instrumental means, which implements the viewed approach, a package of applied programs FuzzyLogicToolbox of MatLab computer mathematics environment can be recommended; it allows creating systems of fuzzy logical conclusions and fuzzy classifications with possibility of their integration into Simulink program. The basic notion of FuzzyLogicToolbox is FIS-structure which contains data for functional expression of "inputs-outputs". The structure of received system of fuzzy logical conclusion is presented in Figure 1.

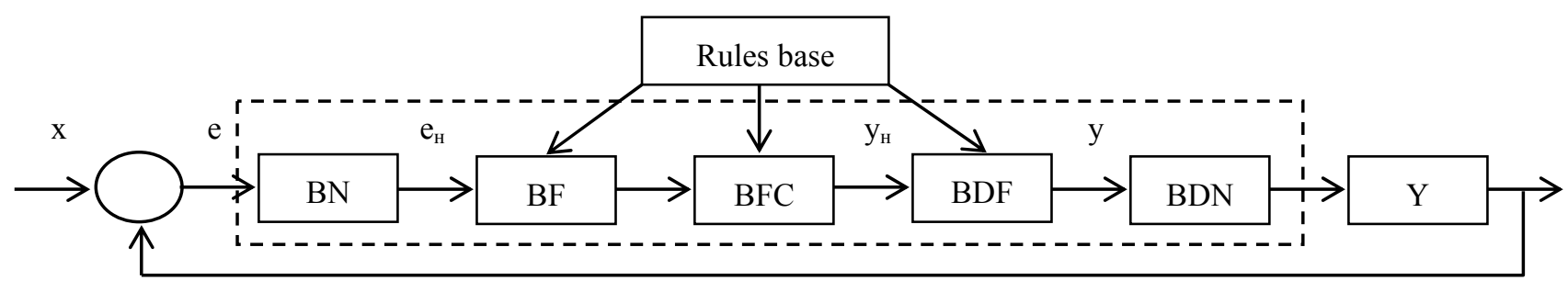

Figure 1. Algorithm of the system of fuzzy logical conclusion

Figure 1 shows $\mathrm{X}$ - input sharp vector;

$\mathrm{BN}$ - block of normalization. The input sharp signal of vector $\mathrm{s}$ is multiplied by scale coefficient $\mathrm{k}_{\text {e.н. }}<1$ and transforms for interval, limited by, for example, $[-1,+1]$;

$\mathrm{NF}$ - block of fuzzification forms the value of function of membership function which corresponds to the normed value $\mathrm{e}_{\mathrm{n}}$.

BFC - block of fuzzy conclusion, in which - based on fuzzy information about vector - a conclusion is made as to corresponding fuzzy variety of values $y$; here, a so called inference-procedure is realized, in the process of which the conclusions of particular rules are aggregated. The result of aggregation is "cut" fuzzy varieties.

BDF, BDN - blocks of defazzification and de-norming perform the opposite procedures: according to several "cut" membership functions, a sharp value of normalized value $\mathrm{y}_{\text {н }}$ and corresponding unnormalized value $у=\mathrm{y}_{\text {н }}$ $/ \kappa_{\text {у.н. }}\left(\kappa_{\text {у.н. }}<1\right)$ are found;

$\mathrm{Y}$ - output sharp vector of manageable parameters of food security.

As the output data for evaluation, analysis, and visualization of parameters of the studied object in the developed system of fuzzy-multiple models of food security and for their formalization in the system of computer mathematics MatLab, the annual volume of production, consumption, and import of food products in Russia in 2014 (Table 1) was used.

Table 1. Annual output of production, consumption, and import of food products in Russia in 2014, million $\mathrm{kg}$

\begin{tabular}{cccc}
\hline Product & Production & Consumption & Import \\
\hline Meat and meat products & 53 & 72 & 19 \\
Milk and dairy products & 115 & 254 & 139 \\
Bread and flour products & 71 & 123 & 52 \\
Fruits & 34 & 95 & 61 \\
Vegetables & 57 & 129 & 72 \\
\hline
\end{tabular}

Based on the output data of the model of food security, the directions for perfecting the food system of the country under the conditions of uncertainty are determined. In the process of mathematical modeling of food security, three levels of values for each of the viewed indicators were taken into account at first - "marginal"; "critical", "high". Formalization of nominal indicators, determined not on quantitative but qualitative level, was also performed with the use of membership functions, set by experts. 
At the second stage of modeling of the level of food security, the values (marginal, critical, high) of the food security level were determined. In order to determine the type and form of the above membership functions for each variable, they were approximated by universal dependence

$$
\mathrm{y}(\mathrm{x})=\sum_{i=1}^{N} \phi_{i}(x) * Q_{i}
$$

where $\mathrm{f}(\mathrm{x})$ - function of normal distribution of centered and normalized random value $\mathrm{x}$,

$\mathrm{Q}-\boldsymbol{i} \boldsymbol{-} \boldsymbol{\boldsymbol { \lambda }}$ derivative from function of normal distribution.

For quantitative description of elements of modeled system, two multitudes are used:

- fuzzy situations from the environment of possible states of elements;

- relations between elements.

Each of elements $\boldsymbol{p}_{\boldsymbol{i}}$ of the modeled system from basic multitude $\boldsymbol{B}_{\boldsymbol{t}}$ corresponds to certain linguistic variable $\mathrm{LV}\left(\mathrm{r}_{\mathrm{i}}, \mathrm{B}_{\mathrm{i}}\right) . \mathrm{LV}$ is determined at term-multitude $\left\{\mathrm{r}_{\mathrm{i}}, \mathrm{M}_{\mathrm{i}}\right\}$, which is a set of linguistic values, characterizing typical states of element. Quantity of typical states of element is marked as $\mathrm{M}_{\mathrm{i}}$. In order to describe the terms $\mathrm{r}_{\mathrm{i}, \mathrm{k}}, \mathrm{k}=1, \boldsymbol{M}_{\mathrm{t}}$, which correspond to values of element p., fuzzy membership functions from multitude $\mathrm{M},=\left\{\mathrm{m}(\mathrm{b}), \boldsymbol{b} \in \mathrm{B}_{\mathrm{i}}\right\}$ are used.

Connections $v\left(p_{i}, p_{j}\right)$ between typical states of each pair of elements are set by one of the values of term-multitude of linguistic variable $\left.\left(v\left(p_{i}, p_{j}\right), r_{v(p i, p j)}, B_{v(p i, p j}\right)\right)$, where $r_{v(p i, p j)}$ - term-multitude of linguistic variable $\mathrm{v}\left(\mathrm{p}_{\mathrm{i}}, \mathrm{p}_{\mathrm{j}}\right)$.

Cause relations between each pair of elements $\left(\mathrm{p}_{\mathrm{i}}, \mathrm{p}_{\mathrm{j}}\right)$ from variety of connections $\boldsymbol{V}=\left\{\mathrm{v}\left(\mathrm{p}_{\mathrm{i}}, \mathrm{p}_{\mathrm{j}}\right)\right\}$ are formed as oriented graph. By setting connections between elements through membership functions, it is possible to receive productional models, characterized by varieties of fuzzy rules.

Membership functions for each variable at each term are set by correspondencies:

$$
\mathrm{m}_{\mathrm{k}}(\mathrm{x})=\left\{\mathrm{m}^{\mathrm{L}}(\mathrm{x})=\exp \left(-\left(\left(\mathrm{c}_{\mathrm{k}}\right) / \mathrm{o}^{\mathrm{L}}{ }_{\mathrm{k}}\right)^{2}\right), \mathrm{x}<\mathrm{c}_{\mathrm{k}} ; \mathrm{m}^{\mathrm{R}}{ }_{\mathrm{k}}(\mathrm{x})=\exp \left(-\left(\left(\mathrm{x}-\mathrm{c}_{\mathrm{k}}\right) / \mathrm{o}^{\mathrm{R}}{ }_{\mathrm{k}}\right)^{2}\right), \mathrm{x} \geq \mathrm{c}_{\mathrm{k}}\right\}
$$

Thus, variety of terms and membership functions of input and output variables are determined by the above limits of terms $\left[\Gamma_{k}^{\mathrm{L}}{ }_{\mathrm{k}}, \Gamma_{\mathrm{k}}^{\mathrm{R}}\right]$.

During implementation of the procedure of expert evaluation, the set of rules $\boldsymbol{R}_{\boldsymbol{j}}, \boldsymbol{j}=1, \boldsymbol{N}$ is formed, each of which corresponds to membership functions of conditions and consequence. At that, rules which include coinciding consequences and relating to general interrelation, are grouped into common rule with the help of operations of logical summing.

Quantitative measure of the result of interconnection between elements is determined on the basis of procedures of fuzzy conclusion. Fuzzy rule is presented as $\boldsymbol{A} \rightarrow B$. Condition $\boldsymbol{A}$ can be presented as:

$$
\text { If }\left(\mathrm{x}_{1} \in \mathrm{A}\right) \mathrm{AND} \ldots\left(\mathrm{x}_{\mathrm{j}} \in \mathrm{A}_{\mathrm{j}}\right) \mathrm{AND} \ldots\left(\mathrm{x}_{\mathrm{M}} € \mathrm{~A}_{\mathrm{M}}\right) \text { then }\left(\mathrm{y} € \mathrm{~B}_{\mathrm{j}}\right)
$$

In order to receive output level of activation, the logical multiplication is used:

$$
\mathrm{m}_{\mathrm{A}}^{\mathrm{j}}(\mathrm{x})=\min _{\mathrm{i}}\left(\mathrm{m}_{\mathrm{A}}\left(\mathrm{x}_{\mathrm{i}}\right)\right.
$$

Aggregated membership function is determined by logical summarizing

$$
\mathrm{m}_{\mathrm{B}}(\mathrm{y})=\max _{\mathrm{j}=1, \mathrm{~N}}\left(\mathrm{~m}_{\mathrm{A}}^{\mathrm{j}}(\mathrm{x}) \mathrm{m}_{\mathrm{B}}^{\mathrm{j}}(\mathrm{y})\right)
$$

Point estimation of the result is determined as to the center of the sphere:

$$
Y_{C}=\left(\int_{y} m_{B}(y) y d y\right) /\left(\int_{y} m_{B}(y) d y\right)
$$

Specifying input vector of influence through $\mathbf{X}=\left(\boldsymbol{x}_{\boldsymbol{k}}\right), \boldsymbol{k}=1, \boldsymbol{K}$, and resulting vector as $\mathbf{Y}=\left(\boldsymbol{y}_{\boldsymbol{t}}\right) 1, l=1, \boldsymbol{L}$, it is possible to put the result of functioning of modeling system as

$$
\boldsymbol{Y}=\boldsymbol{F}(\boldsymbol{X}, \boldsymbol{U}, \boldsymbol{W}),
$$

where $\mathrm{W}$ - internal and external factors;

$\mathrm{U}$ - control actions.

Accounting of feedback in the modeled system is realized by recurrent dependence

$$
\boldsymbol{Y}(\mathrm{t})=\boldsymbol{F}(\boldsymbol{X}(\mathrm{t}-1), \boldsymbol{Y}(\mathrm{t}-1), \boldsymbol{U}(\mathrm{t}-1), \boldsymbol{W}),
$$

where $\boldsymbol{t}$ - year of system formation. 
Mathematical model (7) or (8) allows modeling the functioning of the system through setting corresponding components of vector X.

Realization of supposed food model allows receiving integral evaluation of the state of food security and determining comparative characteristics of volumes of threats to food security on the basis of their automatized estimation.

In order to receive generalized indicator of food security, it is possible to use additive fold in the form of linear combination of private criteria-indicators:

$$
\mathrm{S}=\sum_{j=1}^{J} \sum_{i=1}^{I} K_{i} X_{i j}
$$

where $\boldsymbol{X}_{\boldsymbol{i} \boldsymbol{j}}$ - value of particular indicator;

$\boldsymbol{K}_{\boldsymbol{i j}}$ - "weight" of particular indicator;

$\boldsymbol{I}, \boldsymbol{J}$ - quantity of indicators of blocks in the system of indicators.

Realization of the described model with the use of integral indicator (9) allows implementation of typification of threats to food security. Areas of values of food security indicators can be divided into 3 classes:

(1) high security class - characterized by relatively weak influence of threats, prevented by planned influences of the management system or regulatory market processes.

(2) class of allowable level of security - significant influence of threats, requiring prompt and expensive measure for neutralization and elimination of emerging threats. These influences are mainly within the limits of resource capabilities of the subject.

(3) class of critical level of security - when the system cannot cope with them alone and in time. Violating threshold values by great numbers or by all indicators characterizes the full excess of allowable level of food security.

The final stage of determining the level of food security provision at the level of the country is recommendations as to performance of the measures for prevention of damage and minimization of losses.

\section{Results}

Strategy of development of any country's economy supposes the purpose of achieving and preserving food security which is determined as the state's capability, guaranteed by corresponding resource potential, to satisfy independently from external and internal conditions and in stable manner - the need of country's population on the whole and of each citizen for food products and drinking water in volumes, assortment, and quality, sufficient for full physical and social development, health support, and provision of expanded reproduction. The problem of provision of food security remains topical since the start of liberalization of foreign economic policy in Russia (Popkova \& Tinyakova, 2013a). Modern criteria of food security include the share of expenses for food in general expenses of particular groups of population, territorial accessibility of products (measured by comparing the level of retail prices for similar products in different regions of the country), level of "comfort" of food (share in consumption of modern products which reduce losses and save time for work in household), level of "naturality" and good quality of products, influence of food quality on health and life span, including products received with the help of genetic engineering and biotechnologies (Popkova \& Tinyakova, 2013b).

The stated criteria of food security cause its dependence on the state of food market which is defined - in broad aspect - as activity, related to production and realization of food products. An important component of the strategy of development of food market is the strategy of forming product resources which is directed - from the positions of provision of food security - at the creation of strategic and operative reserves of food and satisfaction of country's population needs for food products, primarily, by means of own resource potential and not import.

The situation in the food market is strongly influenced by import of agricultural raw materials and food. Over 2000-2014, their import in Russia grew by 2.7 times. In 2006, the volumes of export of agricultural production grew by $5.8 \%$, as compared to 2005 , the volumes of import - by $16.6 \%$. As a result, the gap between export and import grows (Popkova et al., 2013).

At present, the share of export of agricultural production in general export of Russia is just $2.2 \%$. Export of agricultural production in non-CIS countries grows with higher rates, as compared to export to CIS countries - it constitutes $50 \%$ of the total volume of export supplies in this group of products. Over 2004-2014, the growth rates of agricultural production import constituted $56.0 \%$, while its manufacture in all categories of economy grew only by $27.2 \%$ (Rogachev et al., 2014). 
It is assumed that the country loses its food security if the share of imported production in the total volume of consumed production exceeds 20-25\% (Garthwaite et al., 2015). In Russia, this share constituted $40 \%$ in 2000 . According to economists' estimates, the share of imported meat in the volume of meat reserves in 2014 reached $50 \%$ (in $2004-14 \% ; 2008-32 \% ; 2010-48 \%$ ) and continues growing. The share of meat by-products and waste in the total volume of processed production constitutes around $35 \%$. These tendencies lead to sale crisis, bankruptcy of the Russian food producers, and catastrophic reduction of livestock number in agriculture (Rogachev et al., 2014).

There are difficulties not only with raw material for food industry but also with production capacities which allow processing the raw material into final product. Thus, RF suffers losses, exporting corn and importing products, manufactured on the basis of corn. At present, according to experts, 1 ton of exported flour corresponds to 100 tons of exported corn. As a result, capacities of milling enterprises are loaded only by $60 \%$. Manufacture of cattle breeding production reached only half of the level of 1990 (Mazaeva, 2012). At the same time, in particular spheres, like production of poultry meat, there was a growth by $15 \%$ in 2014 , as compared to 2008 (Rogachev et al., 2014).

Poultry, pork, lamb, butter, and milk-powder are the products which are capable of not only substituting imported production but of being exported to foreign markets. Statistical data shows that import of the stated products continues to grow. Thus, in 2014, import of lamb constituted 14.9 thousand tons, as compared to 6.9 thousand tons in 2013, i.e., it grew by more than twice; pork - 661.1 thousand tons and 584.9 thousand tons (growth by 13\%); butter - 164.8 thousand tons and 132.8 thousand tons (growth by $27.8 \%$, correspondingly) (Rogachev et al., 2014).

Resources of fresh and frozen meat, cheese, and butter are formed over the recent years by means of import. In 2014 , the share of import in manufacture of these products constituted $71.2 \%, 62 \%$, and $65 \%$, correspondingly. Domination of imported production leads to growth of prices for the types of food products, production of which reduced in 2000-2006, as compared to 1995. According to the data of Federal customs service, the average contract price for beef, purchased in non-CIS countries, constituted USD 2,382 per ton in 2014, which is by 1.9 times more than the corresponding level of 2013. The price for pork over this period grew by 1.6 times, the price for poultry meat - by $12.4 \%$ (Rogachev et al., 2014).

The Russian Federation has an unsatisfied internal demand. This demand comprises the potential for market growth for Russian manufacturers. Low profitability of agriculture remains a difficult issue which hinders the Russian manufacturers' entering foreign markets and strengthening of positions in the internal market. In 2014, the number of unprofitable agricultural organizations constituted $40 \%$ of their total number. Profitability of production of milk $(1.5 \%)$ and pork $(22 \%)$ is still very low; profitability of vegetables $(3.31 \%)$ is clearly insufficient; production of beef is still unprofitable (-10\% according to the data of 2014) (Rogachev et al., 2014).

\section{Discussion}

Over the recent years, the problem of food products' safety for consumers became sharp in Russia, which is caused by growing supplies of dangerous and low-quality food products in the market. According to National fund for consumer rights protection, more that $40 \%$ of imported food products are falsified in food and outdoor wholesale markets. In this situation, consistent import substitution of food products and gradual reduction of their share in the Russian market is one of the directions of solving this problem (Maitra \& Rao, 2015).

The reasons for penetration of low-quality import products into the Russian market are lack of strict customs control and entrepreneurs' wish to gain quick profit. Due to that, low-quality products past their sell-by date and without true information in Russian language are purchased. Raw recourses base of processing and food industry is supplied with imported raw materials. Thus, for example, Amur meat processing enterprises work with import raw materials (primarily from China, Argentina, and Brazil) which is not of high quality (He, 2015).

Consequently, Russia faces the problem of import substitution. At that, it should be noted that due to its size, quantity of population, and large internal market, possessing their own sources of raw materials and energy, our country could cease to be an importer of most of food products (meat, sugar, milk, etc.).

As is well-known, the policy of import substitution is one of the forms of protectionism, i.e., state protection of particular spheres of national economy from foreign rivals. Researchers, which criticize this policy, give the following argument.

In order to direct the flows of investments in these spheres, the state sets high import duties for foreign companies' products. As the products, which are manufactured under these conditions, are not competitive in the external markets, it cannot be exported (Jacknowitz et al., 2015). Still, in this case, together with gaining 
"independence" from the import of consumer goods and semi-finished products, the state falls into the "dependence" on the import of raw materials and equipment, which is negatively reflected on the country's payment balance.

As the protected spheres receive a lot of invested capital, the payment for imported equipment requires foreign currency which is expropriated from enterprises of raw materials export, traditional for Russia; but as the capital is invested in less effective enterprises, the growth of export sector is slowed down. This inevitably leads to reduction of economic growth.

Over the last two decades, the import of meat, fish, and raw sugar grew substantially. The most difficult situation arose in the internal meat market, where the share of import in the resources has a sustainable tendency for growth from $45.6 \%$ in 2014 to $63.8 \%$ in 2014 (Rogachev et al., 2014).

Prohibitive measures as to the import are, as a rule, ineffective, and import substitution should be a result of growing demand for domestic products, due to the growth of their consumer qualities. Moreover, the policy of import substitution can lead to uncompetitiveness of the Russian enterprises and unreasoned expenses of the budget and population; besides, it doesn't always lead to support for agricultural manufacturer. For example, strive for ousting imported sugar from the Russian market led to the fact that we pay double price for it, as compared to the European countries; at that, production of sugar beet drops annually, and imported raw materials are used more and more for sugar production.

In order to evade tough economic and social consequences, it is necessary to create and realize state import substitution programs at the federal, regional, and district levels which should clearly reflect the set goals, tasks, and sequence of actions, and main directions of food import substitution. In the process of development of these programs, it is necessary to take into account specific peculiarities of agricultural production of country and specific region, as well as climatic and natural conditions of the Russian production.

Implementation of these import substitution programs will stipulate the increase of competitiveness of production, overcoming critical dependence of the Russian economy on production import, and solving the problem of the provision and strengthening of food security.

\section{Conclusion}

Thus, in modern Russia, the share of imported production in the volume of consumed production exceeds $50 \%$ and continues growing. Consequently, there is unsatisfied internal demand. This demand comprises the potential for market growth for Russian manufacturers. Low profitability of agriculture remains a difficult issue which hinders the Russian manufacturers' entering foreign markets and strengthening of positions in the internal market.

The research that was conducted on the basis of usage of fuzzy \& multiple methods and possibilities for solving the tasks of evaluation allowed taking into account qualitative characteristics of food security and transforming them into numerical form, for conduct of scenario analysis. As a result of the research, it was found that modern Russia faces the problem of food security. It can be solved with the help of import substitution.

\section{References}

Garthwaite, K. A., Collins, P. J., \& Bambra, C. (2015). Food for thought: An ethnographic study of negotiating ill health and food insecurity in a UK foodbank. Social Science and Medicine, 132(1), 38-44. http://dx.doi.org/10.1016/j.socscimed.2015.03.019

He, J. (2015). Chinese public policy on fisheries subsidies: Reconciling trade, environmental and food security stakes. Marine Policy, 56(1), 106-116. http://dx.doi.org/10.1016/j.socscimed.2015.03.019

Jacknowitz, A., Morrissey, T., \& Brannegan, A. (2015). Food insecurity across the first five years: Triggers of onset and exit. Children and Youth Services Review, 53(1), 24-33. http://dx.doi.org/10.1016/j.childyouth. 2015.03.012

Maitra, C., \& Rao, D. S. P. (2015). Poverty-Food Security Nexus: Evidence from a Survey of Urban Slum Dwellers in Kolkata. Source of the World Development, 72(1), 308-325. http://dx.doi.org/10.1016/j. worlddev.2015.03.006

Mazaeva, T. I. (2012). Modern state of cattle breeding in view of food security. Bulletin of University (State University of Management), 1(1), 59-63.

Mazaeva, T. I., \& Rogachev, A. F. (2012). Mathematical modeling and analysis of the processes of implementing technological innovations in view of economic security. Economy and entrepreneurship, 5(28), 296-298. 
Popkova, E. G., \& Tinyakova, V. I. (2013a). New Quality of Economic Growth at the Present Stage of Development of the World Economy. World Applied Sciences Journal, 5(1), 617-622.

Popkova, E. G., \& Tinyakova, V. I. (2013b). Drivers and Contradictions of Formation of New Quality of Economic Growth. Middle-East Journal of Scientific Research, 11(1), 1635-1640.

Popkova, E. G., Morkovina, S. S., Patsyuk, E. V., Panyavina, E. A., \& Popov, E. V. (2013). Marketing Strategy of Overcoming of Lag in Development of Economic Systems. World Applied Sciences Journal, 5(1), 591-595.

Rogachev, A. F., \& Shokhnekh, A. V. (2015). Genesis of mathematical models of econophysics as a path to food security. Audit and financial analysis, 1(1), 410-413.

Rogachev, A. F., Skiter, N. N., Shokhnekch, A. V., \& Glinskaya, O. S. (2014). Economic and mathematical modeling of tax mechanisms of regional ecological security. Audit and financial analysis, 14(6), 140-147.

\section{Copyrights}

Copyright for this article is retained by the author(s), with first publication rights granted to the journal.

This is an open-access article distributed under the terms and conditions of the Creative Commons Attribution license (http://creativecommons.org/licenses/by/3.0/). 